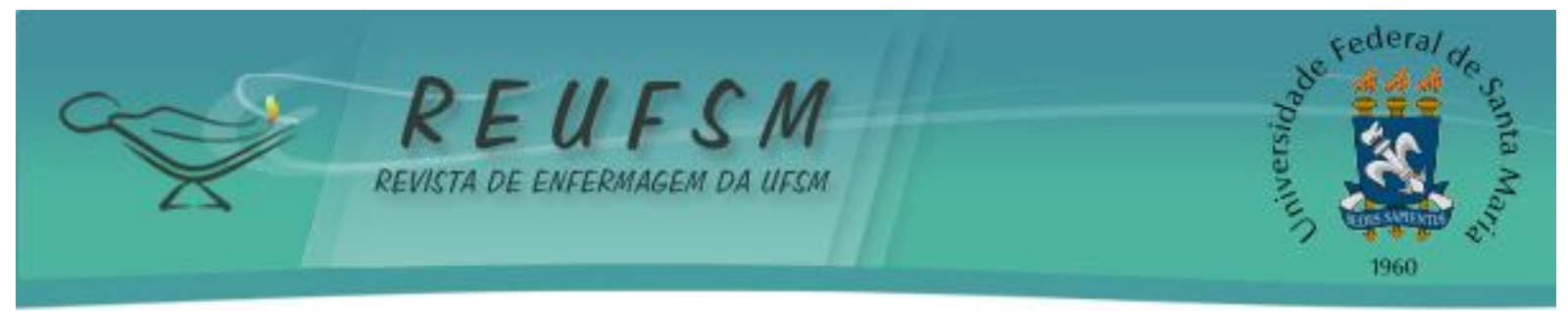

ARTIGO ORIGINAL

\title{
CONHECIMENTOS E CONDUTA DOS AGENTES COMUNITÁRIOS DE SAÚDE FRENTE AOS PRIMEIROS SOCORROS
}

COMMUNITY HEALTH AGENT KNOWLEDGE AND CONDUCT TOWARDS FIRST AID

\section{EL CONOCIMIENTO Y LA CONDUCTA DE LOS AGENTES COMUNITARIOS DE SALUD FRENTE A LOS PRIMEROS SOCORROS}

\author{
Juliana Alice de Oliveira Ventorini ${ }^{1}$ \\ Marcio Rossato Badke \\ Silvana Bastos Cogo ${ }^{3}$ \\ Susane Flôres Cosentino ${ }^{4}$ \\ Vinicius Ornel dos Santos ${ }^{5}$
}

RESUMO: Objetivo: verificar o conhecimento dos Agentes Comunitários de Saúde (ACS) em relação aos primeiros socorros, em um município do Norte do Rio Grande do Sul e identificar as principais situações de urgência e emergência que estes tenham presenciado em seu trabalho. Método: pesquisa qualitativa, exploratório/descritiva, realizada em agosto de 2010, por meio de entrevista semi estruturada, cujos resultados foram analisados por análise temática. Resultados: participaram dez ACS, selecionados por amostragem intencional, dos quais, sete relataram ter presenciado alguma situação de primeiros socorros em seu trabalho. Esses entrevistados ainda referiram ter intervido no ocorrido ao menos com o ato de chamar o socorro. Quanto as ações desses sete, em situação de parada cardiorrespiratória, constatou-se que os participantes acreditavam que a vítima estaria morta, devido à ausência de pulso e respiração. Conclusão: os ACS possuem conhecimento em situações emergenciais, mas muitas vezes insuficientes, necessitando de maiores informações.

Descritores: Enfermagem; Primeiros socorros; Emergências.

ABSTRACT: Objective: to verify the knowledge of Community Health Agents (CHA) in relation to first aid in a city located in northern Rio Grande do Sul, Brazil and identify the main urgent and emergency situations that they have witnessed in their work. Method: exploratory/descriptive qualitative study conducted in August 2010, through semi structured interviews, the results were analyzed using thematic analysis. Results: the participants were ten CHA selected by intentional sampling; seven reported having witnessed a first aid

\footnotetext{
${ }^{1}$ Enfermeira. Pós Graduando em Urgência e Emergência Hospitalar pelo Centro Sul-Brasileiro de Pesquisa, Extensão e Pós-Graduação (CENSUPEG). Email: jujuventurini@gmail.com

${ }^{2}$ Enfermeiro. Professor Assistente do Departamento de Enfermagem da Universidade Federal de Santa Maria. Especialista em Saúde Pública. Mestre em Enfermagem pelo PPGEnf/ UFSM. Membro do Grupo de Pesquisa "Cuidado Saúde Enfermagem". Email: marciobadke@yahoo.com.br

${ }^{3}$ Enfermeira. Professora Assistente do Departamento de Ciências da Saúde do Centro de Educação Superior Norte do RS (CESNORS) da Universidade Federal de Santa Maria (UFSM). Especialista em Cuidado Intensivos. Mestre em Enfermagem pelo PPGEnf/ UFSM. Doutoranda em Enfermagem do Programa de Pós-Graduação da FURG. Membro do Núcleo de Estudo e Pesquisa em Enfermagem e Saúde (NEPES). Email: silvanabastoscogo@yahoo.com.br

${ }^{4}$ Enfermeira. Mestre em Enfermagem pela UFSC. Doutoranda pelo Programa de Doutorado Interinstitucional "Novas Fronteiras" UNIFESP/UFRJ/UFSM. Professora Assistente do Departamento de Ciências da Saúde do Centro de Educação Superior Norte do RS (CESNORS) da Universidade Federal de Santa Maria (UFSM).Email: susycosentino@hotmail.com

${ }^{5}$ Enfermeiro. Pós Graduando em Urgência e Emergência Hospitalar pelo Centro Sul-Brasileiro de Pesquisa, Extensão e Pós-Graduação (CENSUPEG). Orientador de curso do departamento de enfermagem SENAC/Brusque. Email: vi_suiciniv@hotmail.com
} 


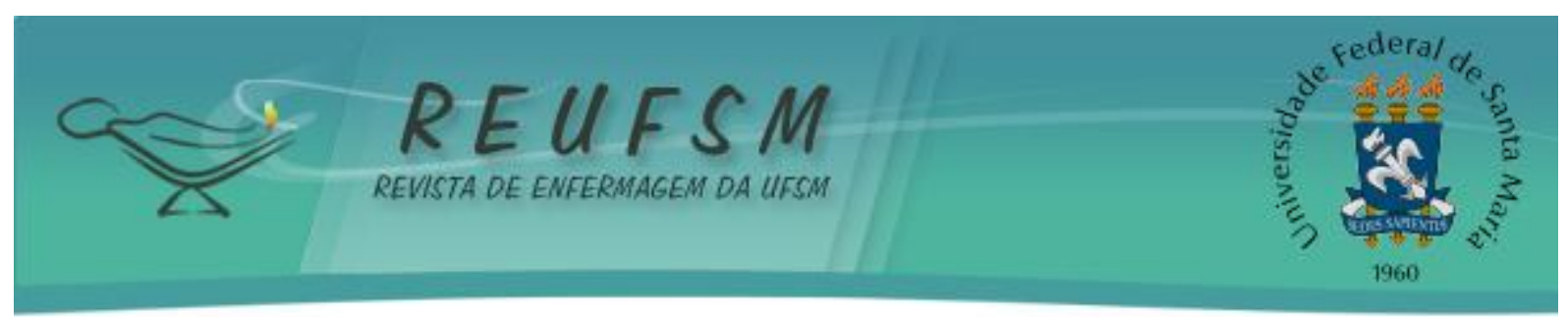

situation at their work. These respondents also reported having intervened in the incident, by at least in the act of calling for help. As for the actions of these seven in a cardiac arrest situation it was found that the participants believed that the victim would be dead due to lack of a pulse and respiration. Conclusion: the CHA are knowledgeable in emergency situations, but often insufficient, requiring greater knowledge.

Descriptors: Nursing; First aid; Emergencies.

RESUMEN: Objetivo: verificar el conocimiento de los Agentes Comunitarios de Salud (ACS) en relación a los primeros auxilios en una ciudad en el norte de Rio Grande do Sul e identificar las principales situaciones urgentes y de emergencia que han presenciado en su trabajo. Método: investigación cualitativa, exploratorio/descriptivo, en agosto de 2010, entrevista semi-estructurada, resultados fueron analizados utilizando el análisis temático. Resultados: los participantes fueron diez ACS seleccionados por muestra intencional, siete informaron haber presenciado situación de primeros auxilios en su trabajo. También informaron de que habían intervenido en el incidente al menos con el acto de pedir el primero auxilio. En cuanto a las acciones de estos siete en una situación de paro cardíaco se encontró que los participantes creían que la víctima estaría muerta debido a la falta de pulso y respiración. Conclusión: los ACS tienen conocimiento en situaciones de emergencia, pero muchas veces insuficientes que requiere mayores informaciones.

Descriptores: Enfermería; Primeros auxilios; Urgencias médicas.

\section{INTRODUÇÃO}

As situações emergenciais que chegam ao sistema de saúde nos dias atuais estão aumentando devido a grande demanda de pacientes com novas doenças trazidas por uma sociedade globalizada, ocasionando grandes filas, onde as pessoas disputam o atendimento.

Nesse contexto, a não distinção de riscos ou graus de sofrimento, faz com que o critério de atendimento seja a hora de chegada e não a situação de emergência do problema, ocasionando muitas vezes a gravidade do caso, levando a morte do paciente. 0 acolhimento com avaliação de risco e vulnerabilidade procura oferecer um bom cuidado, proporcionando ao paciente a resolubilidade, ao incorporar critérios que levam em conta toda a complexidade dos fenômenos saúde/doença, o grau de sofrimento dos usuários e a priorização da atenção no tempo, diminuindo o número de mortes evitáveis, sequelas e internações. ${ }^{1}$

Segundo o Sistema de Acolhimento com Classificação de Risco, ferramenta de organização do serviço de saúde, a prioridade de atendimento é definida pela gravidade, maior risco de agravamento do quadro clínico e sofrimento ou vulnerabilidade. Nesses termos, entendese emergência como toda e qualquer situação em que se necessita de um atendimento imediato identificado pela cor vermelha; já a urgência é considerada uma situação onde necessita-se de um atendimento o mais rápido possível, identificado pela cor amarela. ${ }^{2}$

O setor da saúde tem a responsabilidade de criar soluções para essas demandas, como por exemplo, organizar protocolos em emergências na situação de desastres, assim como desenvolver estratégias que capacitem cada vez mais a população na identificação de situações que comprometam a vida, para que obtenha-se diminuição de agravos à saúde.

Ao se depararem em situações de emergência, pessoas leigas fazem os primeiros socorros, sendo muitas vezes, realizado da forma incorreta, levando assim, ao agravamento da situação do paciente. Neste sentido, qualquer indivíduo que prestar o socorro, deve estar munido de conhecimentos sobre a prática dos primeiros socorros, a fim de evitar agravos à saúde da vítima.

$\mathrm{Na}$ prestação de primeiros socorros, que é o atendimento imediato providenciado à pessoa doente ou ferida e que pode ser realizado pela população em geral, considera-se 


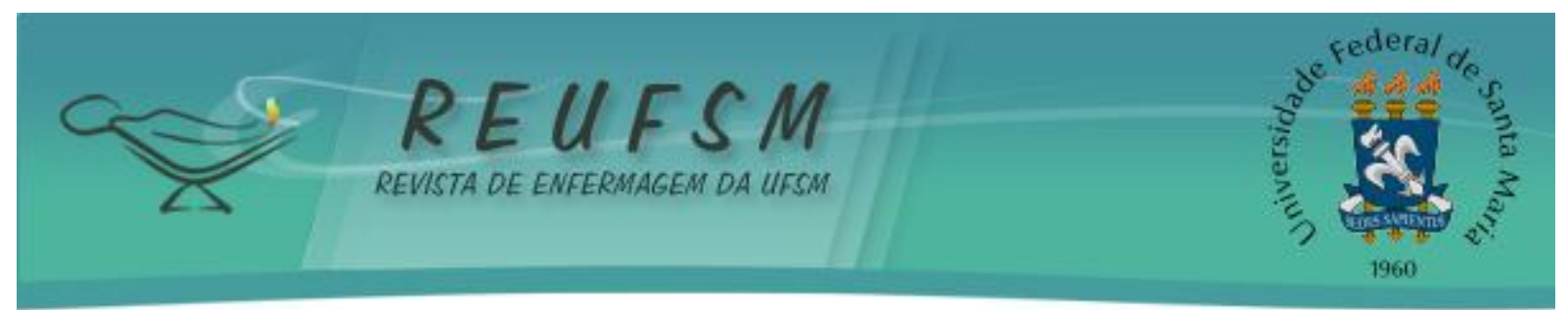

importante que a mesma tenha conhecimentos básicos que possibilitem atuar em situações de urgência e emergência, por isso a necessidade de capacitá-la para agir em tais situações. ${ }^{3}$

As lesões traumáticas estão entre as principais causas de morte e incapacidade, ocorrendo em todas as regiões e países, afetando indivíduos em todas as faixas etárias e categorias de renda e sendo responsáveis por cerca de três milhões de óbitos no mundo anualmente. Essas são tradicionalmente tratadas como "acidentes" inevitáveis, que acontecem ao acaso. Nas últimas décadas, entretanto, a melhor compreensão da natureza destes eventos tem modificado essas velhas atitudes e tanto as lesões intencionais como as não intencionais podem ser prevenidas. ${ }^{4}$ Logo, se faz necessário pensar em formas de prevenção a esses agravos, de modo que o atendimento inicial à vítima possa atenuar prejuízos à vida.

O Programa de Agentes Comunitários de Saúde (PACS) é uma estratégia para atendimento das necessidades de saúde que envolve os agentes comunitários de saúde (ACS) e um enfermeiro para supervisionar as atividades. Os ACS também compõem a equipe mínima de Estratégia de Saúde da Família, realizando visitas domiciliares na área de abrangência produzindo informações capazes de dimensionar os principais problemas de saúde de sua comunidade. ${ }^{5}$ Dessa forma, acredita-se na indispensabilidade da capacitação para que possa intervir em situações de emergências, possibilitando também, ser um transmissor de informações a respeito de primeiros socorros. Nesse sentido, o enfermeiro possui um papel fundamental que é perceber em sua equipe as fragilidades de conhecimentos para que, a partir desse diagnóstico, proponha capacitações que venham ao encontro das necessidades da população. Assim, pode-se conceber uma equipe de profissionais transformadora que leva informação de uma forma clara e simples à comunidade por ela assistida.

Com base em tais considerações, o estudo justifica-se por ter sido proposto a partir de vivências em campo de práticas dos autores, onde observam-se a demanda de usuários, pertencentes à abrangência do PACS, que chegavam ao pronto atendimento do município em situação de urgência e emergência ocorridas no domicílio. Então, surgiu a indagação que remeteu a seguinte questão norteadora: como os ACS entendem, atuam e se comportam frente às situações de urgência e emergência?

0 estudo teve como objetivo verificar o conhecimento dos ACS em relação aos primeiros socorros em um município do Norte do Rio Grande do Sul e identificar as principais situações de urgência e emergência que estes tenham presenciado em seu trabalho.

\section{MÉTODO}

Trata-se de uma pesquisa qualitativa do tipo exploratório-descritiva ${ }^{6-7}$; os sujeitos foram dez ACS pertencentes ao PACS, do referido município, sendo cinco homens e cinco mulheres. Utilizou-se como critério de seleção ser maior de 18 anos, residir no município do estudo e não ter cursos técnicos na área da saúde.

A seleção dos sujeitos da pesquisa se deu por amostragem intencional, já que a população total do PACS era de 21 ACS, sendo que participaram da pesquisa dez ACS, na qual toma-se como amostra os elementos da população que estão mais disponíveis ou voluntários. ${ }^{8}$ Sendo assim, 11 ACS não participaram da pesquisa, destes, cinco tinham curso técnico na área da saúde e seis não quiseram participar do estudo.

A escolha dos ACS se deve ao fato desses serem consideradas pessoas leigas na atuação em primeiros socorros, já que não é obrigatória a capacitação dos mesmos e por estarem próximos da comunidade e conhecerem os problemas por ela enfrentados. Ainda 


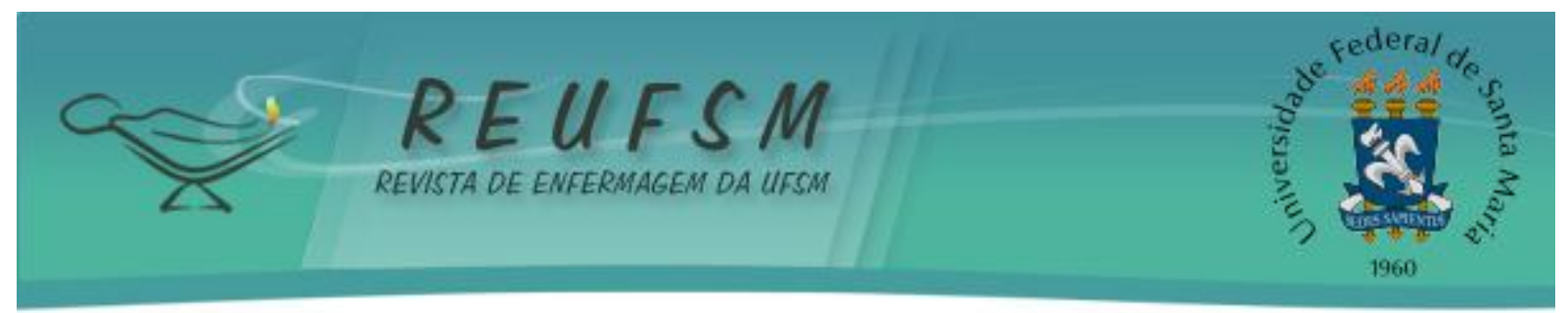

por acreditar que por serem (os agentes) pessoas da comunidade, não só se assemelham nas características e anseios da mesma, como também preenchem lacunas, justamente por conhecerem as necessidades dessa população.

A coleta dos dados ocorreu em agosto de 2010, por meio de uma entrevista semiestruturada, composta por duas partes, a primeira contendo questões fechadas sobre os dados pessoais dos entrevistados e a segunda formada por questões abertas que abordaram temas como: conceito de primeiros socorros, ações em uma situação de parada cardiorrespiratória, desmaios, convulsões e queimaduras. Algumas perguntas foram desdobradas em duas, sendo a segunda realizada somente quando as declarações do entrevistado pudessem remeter a outra. ${ }^{9-11}$ As entrevistas foram agendadas e os ACS assinaram o Termo de Consentimento Livre e Esclarecido e solicitada autorização para gravar as mesmas. ${ }^{12}$ Para preservar a identidade dos entrevistados e os padrões éticos, suas falas foram transcritas com identificação de cores. A pesquisa foi aprovada pelo Comitê de Ética em Pesquisa da Universidade Federal de Santa Maria, no dia 30 de julho de 2010 sob CAAE 0136.0.243.000-10. Os dados foram analisados sob a luz da análise temática considerada uma das técnicas de análise de conteúdo, cuja operacionalidade se distingue em três etapas: a pré-análise, a exploração do material, e o tratamento dos resultados, com a inferência e as interpretações. ${ }^{13}$

Os resultados foram organizados por temas (quatro) e em categorias emergentes (nove), de acordo com as falas dos participantes.

\section{RESULTADOS E DISCUSSÃO}

Para uma melhor interpretação dos resultados, é importante caracterizar os entrevistados, como segue abaixo.

\section{Caracterização dos sujeitos da pesquisa}

Quanto à idade dos entrevistados, constatou-se que varia dos 23 aos 46 anos, sendo que dois deles têm idade entre 41 e 46 anos e os outros oito têm idades inferior a 33 anos, compondo uma equipe jovem.

Outro dado relevante alçado na caracterização dos entrevistados é relativo ao tempo em que estes estão no serviço, o qual variou de um a nove anos, sendo que apenas um dos entrevistados está há um ano no serviço, ao passo que, dos demais, um está há dois anos, seis estão há três anos e dois a nove anos.

Constatou-se que, os entrevistados que estão há mais de dois anos no serviço possuem algum tipo de capacitação na área já citada, porém observa-se esse conhecimento incompleto, justificado pelo fato de que ações em primeiros socorros estão em constante mudança.

Quanto à escolaridade, averiguou-se que seis dos entrevistados possuem o ensino médio completo, três apresentam grau superior incompleto e um, superior completo. Verificou-se ainda que, seis são naturais do município de Palmeira das Missões e os demais dos municípios de Tupanciretã, Nonoai, Porto Alegre e Lages (SC).

Quando interrogados sobre a importância de capacitações em primeiros socorros, a resposta dos entrevistados foi unânime em relação à necessidade de serem realizados cursos que, de acordo com os mesmos, possam abordar temas como: engasgo, convulsão, picadas por animais peçonhentos, acidentes de trabalho, hemorragias, fraturas e reanimação cardiopulmonar.

No sentido de verificar o conhecimento dos ACS em primeiros socorros, foram utilizados os seguintes temas, com suas respectivas categorias: o conceito de primeiros 


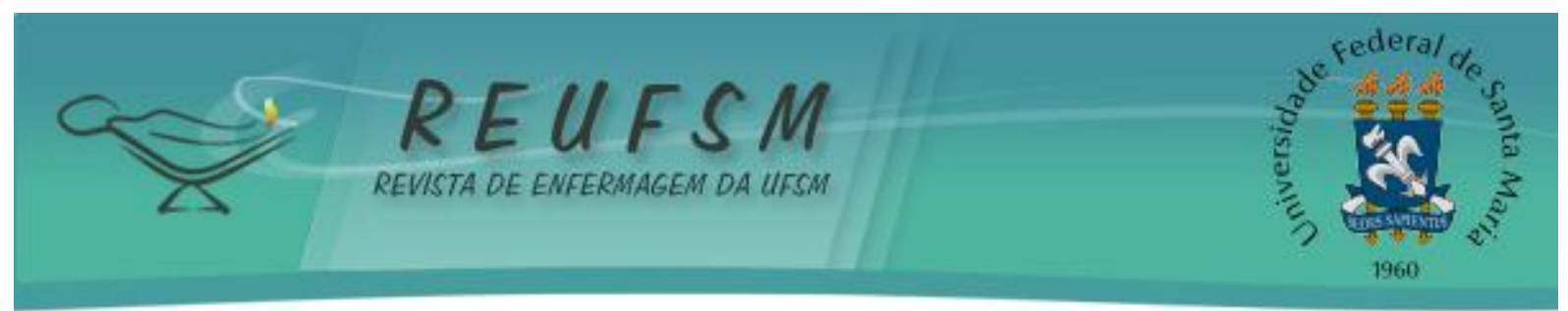

socorros (primeiro atendimento imediato, qualquer pessoa capacitada), situações de urgência e emergência (presenciei uma situação de risco), abordagem a vítima e atuação frente ao socorro prestado (verifico sinais vitais, chamo o socorro, proporciono proteção à vítima, ofereço ventilação) e queimaduras e uso de água (não sei bem os graus, coloco água).

\section{O conceito de primeiros socorros}

$\mathrm{Na}$ busca pela compreensão do conceito de primeiros socorros, por meio das entrevistas, obteve-se durante a análise temática do material o surgimento das categorias: "primeiro atendimento imediato" e "qualquer pessoa capacitada".

\section{Primeiro atendimento imediato}

Com as entrevistas, pode-se verificar que dos dez entrevistados, seis deles, entendem que primeiros socorros são os primeiros atendimentos prestados a pessoa que necessita de cuidado imediato. Isto pode ser visto na fala a seguir:

\section{[...] primeiro socorro quer dizer primeiro atendimento [...]} socorrer a pessoa exatamente no momento imediato [...]. (AZUL)

Verificou-se que grande parte dos entrevistados possui uma noção a respeito do conceito de primeiros socorros, corroborando com a literatura, na qual os primeiros socorros são definidos como sendo os cuidados imediatos que devem ser prestados rapidamente a uma pessoa, vítima de acidentes ou de mal súbito, cujo estado físico põe em perigo a sua vida, com o fim de manter as funções vitais e evitar o agravamento de suas condições, aplicando medidas e procedimentos até a chegada de assistência qualificada. ${ }^{10}$

\section{Qualquer pessoa capacitada}

Quando foram indagados sobre quem deveria prestar o atendimento de primeiros socorros, seis deles responderam que qualquer pessoa capacitada poderia prestar o socorro, isto é, pessoas que passam por um treinamento básico para que não prejudiquem mais a vítima, como mostra a fala a seguir.

[...] todas as pessoas que estejam capacitadas a fazer [primeiro atendimento] [...] independente se são formadas ou não [...]. (CINZA)

A fala transcrita acima corrobora a literatura que refere-se a "qualquer pessoa treinada poderá prestar os primeiros socorros". 10:9 Logo, assume-se o conceito de que qualquer pessoa pode ou mesmo deve prestar o primeiro socorro, sendo que esta deve estar ao menos capacitada para tal, sem ser exclusivamente um profissional da área da saúde.

O entendimento sobre primeiros socorros é de suma relevância no que diz respeito ao tipo de atendimento e quem deve prestá-lo. A pessoa que presta o primeiro atendimento deve saber que as manobras de que fará uso serão do tipo não invasivo e que deve chamar um serviço de emergência sempre que julgar necessário. 


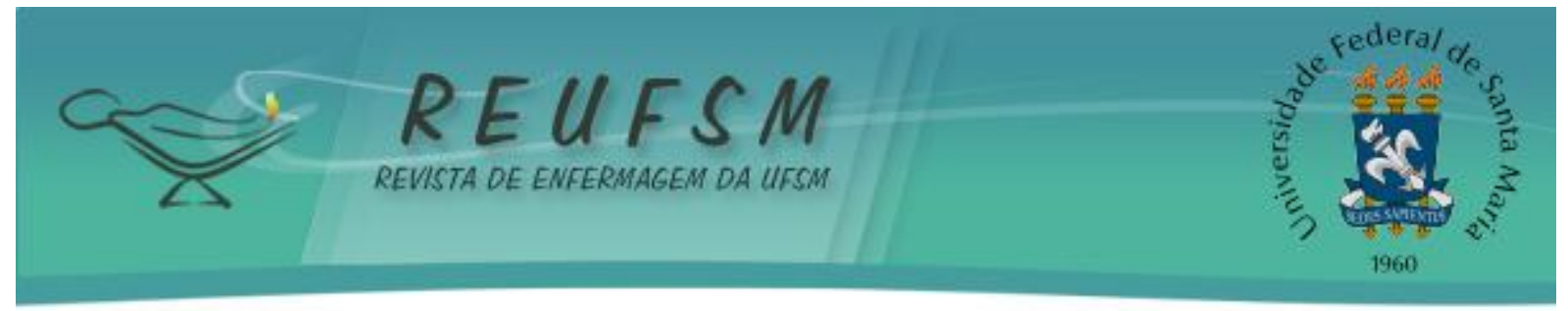

Situações de urgência e emergência

Este estudo tem como premissa que o ACS está sujeito a presenciar com maior frequência, situações de urgência ou emergência e mesmo sem treinamento adequado para a prática de primeiros socorros, auxiliará vítimas em situações emergenciais apenas pelo impulso de solidariedade. ${ }^{1}$ Os entrevistados foram questionados sobre quais situações desta natureza foram presenciadas em seu trabalho. Emergiu a seguinte categoria: "presenciei uma situação de risco". Dos dez entrevistados, sete já haviam presenciado alguma situação em que se fazia necessário o atendimento em primeiros socorros. Devido à relevância da questão, sentiu-se a necessidade de relatar algumas vivências dos entrevistados.

\section{Presenciei uma situação de risco}

Dentre os sete que haviam presenciado alguma situação de urgência ou emergência, dois referiram a crise hipertensiva, o que pode ser observado nas palavras abaixo.

[...] E até tive um caso e não foi muito grave, a pessoa, acho que era mais nervosismo, ela tinha pressão alta. Ela meio que desmaiou, branqueou um negócio assim, tivemos que levar ela num carro urgente para o hospital. (AZUL)

Pode-se inferir que trata-se de uma crise hipertensiva, a qual deve ser considerada uma situação com risco de morte. As urgências hipertensivas devem ser reduzidas em pelo menos 24 horas e, em geral, a pessoa irá apresentar uma pressão arterial diastólica maior que $120 \mathrm{mmHg}$, sem comprometimento de órgãos-alvo. Já a emergência hipertensiva se diferencia da urgência hipertensiva como uma situação em que há elevação crítica da pressão arterial, com progressiva lesão de órgão-alvo, quadro clínico grave e risco de morte. ${ }^{14}$

Desse modo, o simples ato de chamar um socorro especializado ou encaminhar a vítima até um serviço de emergência faz com que a mesma diminua seu risco de morte e complicações.

As outras situações presenciadas pelos ACS foram: hipertermia, ferimento por arma de fogo, hemorragia, acidente por motocicleta e convulsão. Também foi relatado por sete deles, que além de presenciarem a situação, intervieram na cena com, no mínimo, o ato de chamar um serviço de emergência. Alguns ainda realizaram manobras, com equívocos que colocaram a vítima em risco, como se pode observar no discurso abaixo, onde o entrevistado relata ter arrastado a vítima, algo considerado perigoso devido principalmente ao risco de lesão medular.

Eu tive bem na frente da minha casa um acidente de moto, o rapaz se quebrou todo e todo mundo chegava nele. Eu peguei com mais dois, juntei ele, arrastando só um pouquinho para o lado para tirar da rua, e daí liguei para ambulância [...]. (ROXO)

Nesta fala, tem-se uma situação muito comum, onde pelo impacto da cena, muitas vezes, são tomadas atitudes impróprias. Toda pessoa politraumatizada deve ser avaliada como sendo uma vítima potencialmente grave, por ser considerada portadora de lesão raquimedular, sendo esta a principal causa de morte e/ou sequelas grave em $50 \%$ dos casos causados por acidentes automobilísticos. ${ }^{11}$ 


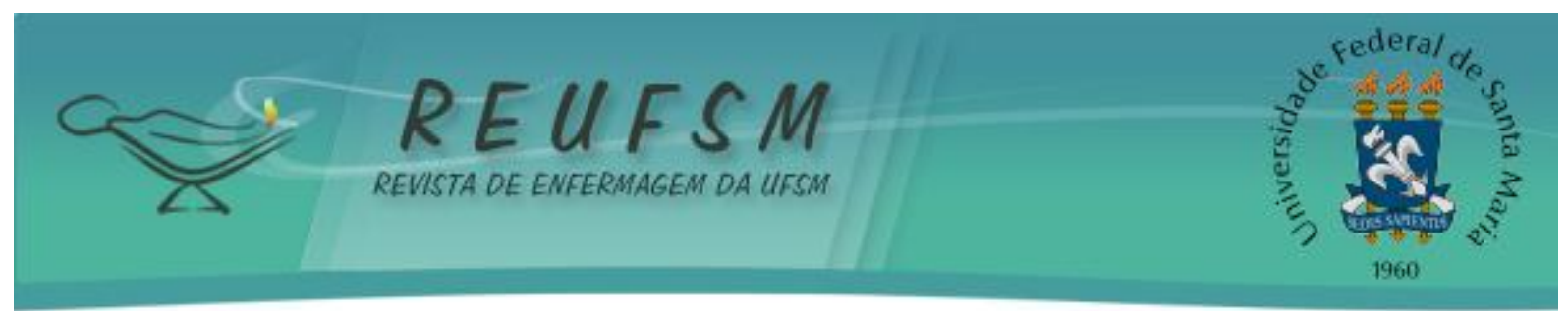

Todos os dez entrevistados demonstraram interesse em saber se suas atitudes foram realizadas de forma satisfatória, tendo em vista que os mesmos referiram à probabilidade de virem a presenciar outras situações nas quais não saberiam como atuar de forma a minimizar agravos.

\section{Abordagem à vítima e atuação frente ao socorro prestado}

Teve-se o objetivo de avaliar se o primeiro atendimento foi realizado de forma satisfatória. As perguntas referiram-se a parada cardiorrespiratória (PCR), convulsão e desmaio por hipotensão.

Quando os entrevistados foram indagados sobre como avaliariam se uma pessoa está viva ou não, surgiu a seguinte categoria:

\section{Verifico sinais vitais} alocução:

Seis, dos dez entrevistados, avaliariam o pulso e a respiração, como demonstra a

Verificaria sinais vitais, aqui no pescoço, assim como pulso e a respiração. Chegaria perto primeiro para ver a respiração encostando o rosto ou a mão próximo ao nariz da pessoa e, no caso, checar aqui o pescoço. (LARANJA)

Um estudo que procurou identificar o nível de informação de uma amostra da população leiga, em uma cidade no interior de São Paulo, revelou que, dos 385 leigos entrevistados, 320 disseram saber reconhecer sinais de vida, sendo que destes apenas 115 leigos citaram pulso e respiração. ${ }^{3}$

Pode-se perceber que, grande parte dos ACS entrevistados, sabem avaliar sinais de vida e os citam corretamente. O reconhecimento de obstrução das vias aéreas, dos sinais de hipoxemia e a resolução desta anormalidade é conduta prioritária no atendimento inicial à vítima. ${ }^{11}$

Para tanto, é necessário saber reconhecer uma PCR, isso se faz avaliando a capacidade de resposta da vítima, ausência de respiração e ausência de pulso carotídeo. ${ }^{15}$

\section{Chamaria o socorro}

Ao serem interrogados sobre o que fariam se fosse constatada a ausência dos sinais previamente citados (pulso e respiração), surge à categoria "chamaria o socorro".

Pode-se observar nas falas que, sete dos entrevistados ao "chamar por socorro" parecem ter lançado mão desse recurso apenas quando não havia mais pulso e respiração, corroborando com as literaturas que referem que há uma quebra no primeiro elo da corrente de sobrevida, o qual corresponde a chamar o socorro antes de aplicar qualquer manobra. ${ }^{15}$

\section{Ai eu chamaria o socorro. (PRETO)}

Outro motivo de chamar por socorro nesta situação é, às vezes, este ser confundido com ligação à polícia e se deve ao fato de sete dos entrevistados acreditarem que a vítima encontrava-se morta, enquanto apenas três referiram ter iniciado reanimação cardiorrespiratória, sendo que estes não sabiam realizar as manobras. 


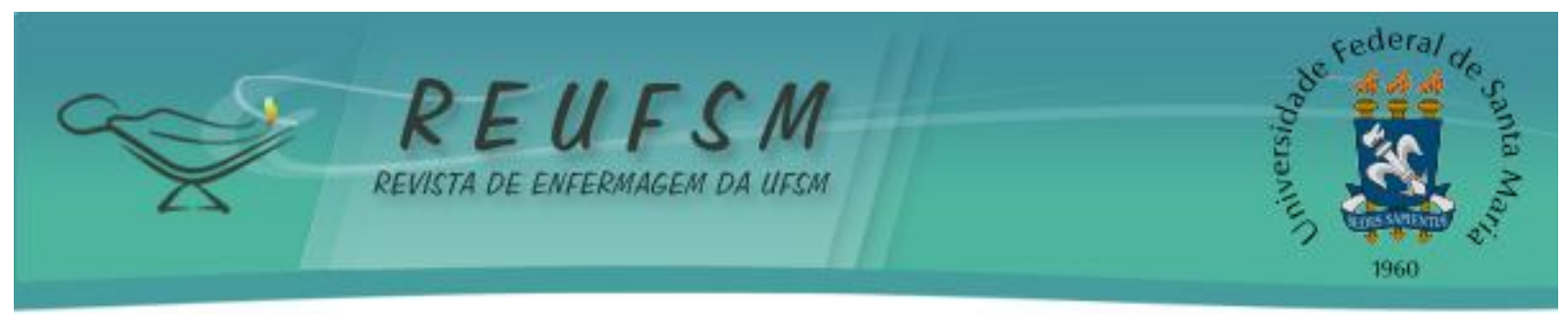

O entrevistado explica sua atitude da seguinte forma:

Acho que no momento eu tinha que ligar para polícia, na dúvida, geralmente a gente liga 190. Porque para saúde não adianta mais, porque ela está morta. (VERDE)

O número de entrevistados que relatou a vítima estar morta quando não constatado pulso e respiração é alarmante, visto que cerca de $30 \%$ das reanimações cardiopulmonares ocorrem em meio pré-hospitalar e quando iniciadas por leigos, estimouse serem salvas seis vidas por cada 100.000 indivíduos, por ano. Estudos apontam para a redução de até $7,5 \%$ da mortalidade em contexto pré-hospitalar, por meio do ensino à população em geral, dos primeiros gestos de socorro em situações de emergência, sobretudo através da implementação de programas de treino de reanimação cardiopulmonar na comunidade. ${ }^{15}$

\section{Proporciono proteção à vítima}

Obteve-se a categoria "proporciono proteção à vítima," quando os entrevistados foram interrogados a respeito do que fariam ao ver uma pessoa em crise convulsiva. A maioria dos entrevistados, nove dos dez, em algum momento de suas falas, referiram esta ação em primeiros socorros, o que pode-se notar na alocução transcrita abaixo.

Ouvi falar que no caso não tem muito que fazer, no momento tirar as coisas do redor da pessoa, só segurar a cabeça para não bater eu acho, no mais é a cabeça para não bater e acabar se ferindo. (LARANJA)

O socorrista deve atuar de forma a tentar evitar que a vítima caia desamparadamente, cuidando para que a cabeça não sofra traumatismo e procurando deitá-la no chão com cuidado, acomodando-a. Também deve-se remover qualquer objeto com que a vítima possa se machucar e afastá-la de locais e ambientes potencialmente perigosos. ${ }^{10}$

Outros três entrevistados além de proporcionarem proteção à vítima, também relataram ser necessário à colocação de algo na boca para que a vítima não "morda a língua".

Boto um pano na boca para não ter perigo de engolir a língua e chamaria o socorro [...]. (VERMELHO)

Observa-se que ainda existem vestígios de informações desfragmentadas, prejudicando, muitas vezes, a assistência, expondo a vítima a um risco ainda maior. Alguns ainda relataram corretamente as ações em primeiros socorros e após se contradisseram em segurar braços, pernas e língua, assim como colocar a cabeça da vítima entre os joelhos.

\section{Ofereço ventilação}

Quando questionados a respeito de como agiriam ao ver uma pessoa desmaiando por hipotensão, cinco dos dez entrevistados responderam "ofereço ventilação", esta categoria pode ser observada na fala que segue a baixo. 


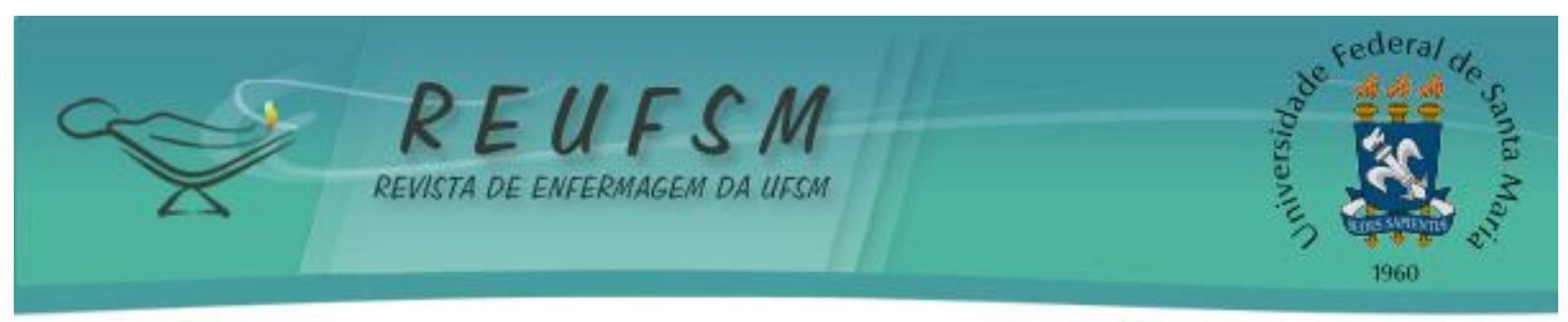

Acontece muito, sei lá! Começaria a fazer um vento nela [vítima], sentaria ela, começaria a abanar ela e já dava um jeito de ligar para alguém me socorrer. Se tivesse deitada levantaria mais o travesseiro dela e deixaria sentada. (ROSA)

Os outros cinco entrevistados deram respostas variadas como, por exemplo, levantar os braços da vítima, oferecer água, colocar sal embaixo da língua e molhar articulações. Em quatro repostas observou-se a menção da manobra de posicionamento da cabeça da vítima entre as pernas, mas acompanhada por atitudes equivocadas, já referidas acima.

Existem duas situações em se tratando de desmaio, uma em que a vítima encontra-se em pé onde o socorrista deve ajudá-la a sentar-se e curvá-la para frente, baixar a cabeça, colocando-a entre as pernas e pressionado-a para baixo. A outra situação é quando a vítima já desmaiou e nesta deve-se manter a vítima deitada colocando sua cabeça e ombros em posição mais baixa em relação ao resto do corpo, afrouxando roupas e deixando o ambiente ventilado. ${ }^{10}$

\section{Queimaduras e o uso de água}

Quando perguntados a respeito de como classificam as queimaduras e qual procedimento adotam nessa situação, surgiram duas categorias: "não sei bem os graus", pelo fato de não ter sido obtida uma resposta completa e correta a respeito da classificação de queimaduras e "coloco água" como sendo a predominante no que diz respeito ao procedimento adotado na situação de queimadura.

\section{Não sei bem os graus}

Oito dos dez entrevistados responderam de forma equivocada sobre classificação de queimaduras. No entanto, todos os dez, citaram existir uma classificação em graus, da qual não sabiam ao certo se a lesão de primeiro grau era a mais profunda ou a de terceiro. No discurso abaixo se observa o referido acima.

Olha, pelo que eu tenho noção assim, uns falam de primeiro, segundo e terceiro grau, agora eu não sei te dizer a ordem delas [queimaduras], mas acho que a de primeiro grau é a mais forte, seria com feridas? (CINZA)

As queimaduras podem ser classificadas em três graus, onde quanto maior o grau, maior a gravidade, pelo fato de mais camadas da pele ser lesadas. ${ }^{11}$

A determinação da profundidade da queimadura pode ser difícil mesmo para o profissional experiente em cuidado de queimadura. A função do leigo no primeiro socorro ao queimado, além de atenuar a queimadura é de investigar como ocorreu a lesão, o agente causador da queimadura, a duração do contato e a temperatura do agente causador. ${ }^{16}$ Assim, o Serviço de Emergência (SE) terá maiores informações podendo classificar de forma fidedigna a profundidade da queimadura, determinando se ocorrerá a epitelização.

Mesmo assim, é importante que o ACS saiba classificar corretamente os graus de queimaduras, para que, ao procurar o SE, que seja uma situação de urgência ou emergência e não por uma lesão que possa ser tratada em uma unidade básica de saúde. Desse modo, espera-se uma diminuição nos números de consultas eletivas nos SE. 


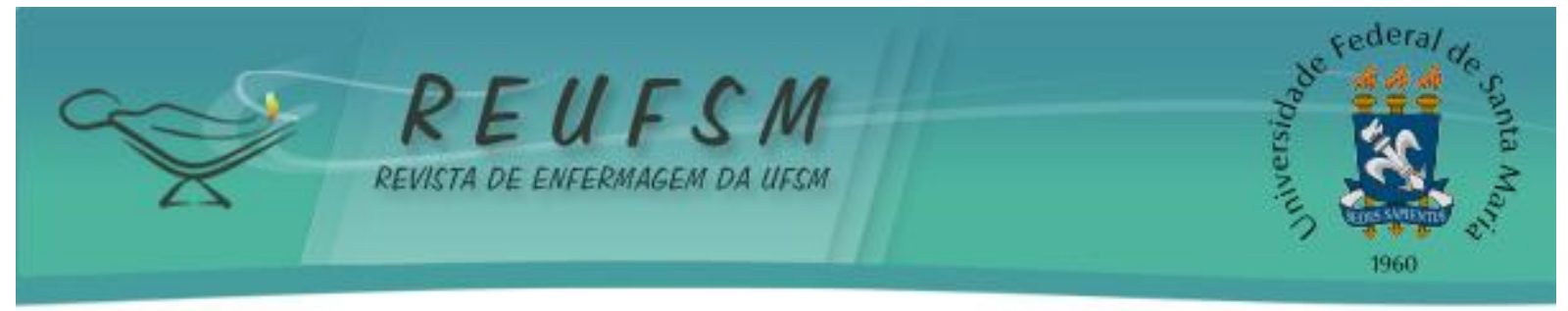

\section{Coloco água}

Ainda sobre o mesmo tema, foram interrogados a respeito de qual procedimento adotariam em uma situação de queimaduras. Cinco dos dez entrevistados responderam "coloco água", sendo esta a categoria predominante.

[...] o aconselhável é não furar as bolhazinhas que cria na pele, segundo o que dizem é uma proteção [...] não enrolar deixando abafado, tem que lavar. Higiene acima de tudo! Eu acredito que seja só colocar água. Existem pomadas também, mas não acredito que passar creme dental, estas coisas adiante, diz que vaselina é uma coisa boa [...] encaminharia para o posto, mas se é na minha casa passo vaselina [...]. (ROSA)

Observa-se na fala uma riqueza de informações, as quais coadunam com a literatura atual, sendo que, mesmo munida de conhecimento, aponta para o uso de uma terapia não recomendada, o uso da vaselina.

Segundo a American Heart Association ${ }^{9}$, os prestadores de primeiros socorros devem lavar os ferimentos e as abrasões com água corrente limpa ou qualquer fonte de água limpa, durante 5 minutos ou mais, até não existir mais sinais de material estranho. Ainda coloca que, se for uma abrasão ou ferimento superficial, o prestador de primeiros socorros pode aplicar um creme ou pomada contendo antibióticos. Portanto, o primeiro socorro visa à interrupção do processo térmico por meio do resfriamento da superfície lesada.

Com base nos achados, reforça-se a necessidade de cursos de capacitação e habilitação da população leiga de forma a garantir o atendimento rápido e eficaz em qualquer situação de emergência, permitindo, ao menos, o acionamento precoce do atendimento especializado. Nesse sentido, a enfermagem tem um papel fundamental, pois uma de suas atribuições é promover ações educativas em saúde, por meio da educação permanente, o enfermeiro capacita sua equipe, realizando trabalhos de assistência, promoção e educação.

\section{CONCLUSÃO}

Esse estudo possibilitou verificar o nível de conhecimento dos ACS em primeiros socorros e constatou que os mesmos possuem conhecimentos incompletos, comprometendo o socorro à vítima, não apresentando adequado entendimento e fundamentação das manobras utilizadas em situações de risco de morte.

Em muitas das respostas, pode ser identificada a presença de conhecimentos de senso comum. Contudo, muitos ACS em situações que presenciaram, agiram pelo impulso da solidariedade, sendo necessário um treinamento adequado, no qual sejam abordadas situações de risco por meio de oficinas práticas com simulações.

Após a coleta de dados, foi realizada uma capacitação prática, a qual contou com a participação dos ACS do município em estudo, sendo abordados temas sugeridos pelos mesmos.

Outro dado intrigante da pesquisa foi que sete dos entrevistados relataram conhecer e avaliar sinais de vida de uma pessoa caída no chão, sendo que, os mesmos sete, julgam estar morta uma vítima que não tenha pulso nem respiração. Diante dessa informação, tal assunto deverá ser objeto de outro estudo mais aprofundado na temática PCR, com vistas a avaliar se o grupo sabe reconhecer corretamente a tríade de diagnóstico de PCR.

Portanto, visto que grande parte dos entrevistados presenciou situações com risco de morte, é essencial a educação dessa classe por meio de treinamentos que visem colocar 


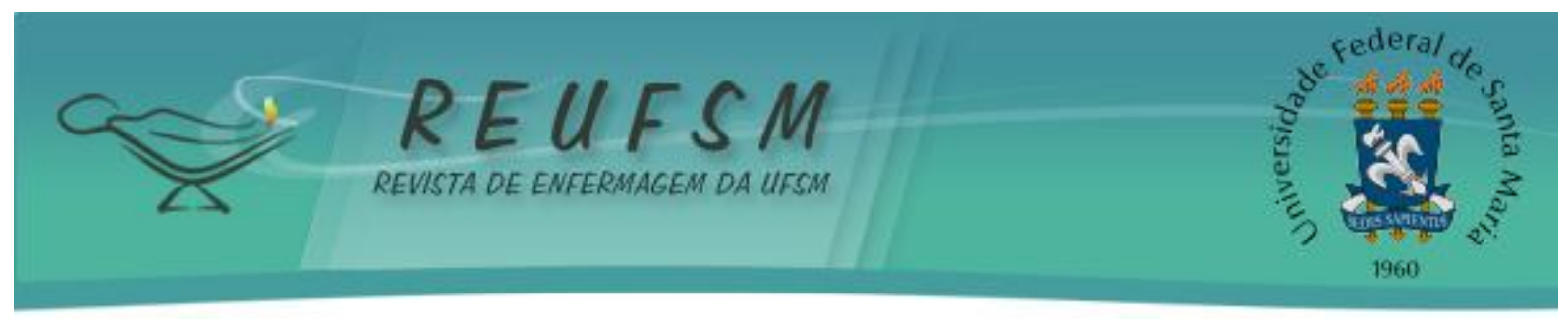

- ACS, em circunstâncias o mais próximo possível da realidade, para que possam não somente agir por impulso, mas que proporcionem atendimento eficaz com melhora da sobrevida da vítima.

Assim, espera-se que esta pesquisa possa contribuir na produção do conhecimento da enfermagem ao levantar deficiências em uma amostra de pessoas (ACS), que possuem um papel cada vez mais importante na sociedade e na saúde, que necessita estar informada sobre como atuar em determinadas situações de emergência e urgência. 0 enfermeiro pode ser agente de mudanças junto a sua equipe para que esta saiba ser resolutiva e contribua na conservação da saúde do outro, capacitando-os.

\section{REFERÊNCIAS}

1. Carneiro SMBM. Atendimento de urgência e emergência na atenção básica: desafio para a estratégia saúde da família [dissertação]. Fortaleza: Universidade Estadual do Ceará; 2009 [acesso em 2012 maio 13]. 71 p. Disponível em: http://rededepesquisaaps.org.br/UserFiles/File/MONOGRAFIAS/atendimentourgencia15_03.pdf.

2. Ministério da Saúde (BR). Secretaria de Atenção à Saúde. Política Nacional de Humanização da Atenção e Gestão do SUS. Acolhimento e classificação de risco nos serviços de urgência. Brasília, DF: Ministério da Saúde; 2009 [acesso em 13 maio 2012]. Disponível em:

http://bvsms.saude.gov.br/bvs/publicacoes/acolhimento_classificaao_risco_servico_urgencia.pdf.

3. Pergola AM, Araujo IEM. O leigo em situações de emergência. Rev Esc Enferm USP [internet]. 2008 dez [acesso em 2010 mar 17];(42):[4]. Disponível em:

http://www.scielo.br/pdf/reeusp/v42n4/v42n4a20.pdf.

4. Ladeira RM. Epidemiologia do trauma. In: Baccarini MTP, Starling SV. Manual de urgências em pronto-socorro. $8^{\mathrm{a}}$ ed. Rio de Janeiro: Guanabara Koogan; 2006. p. 920-3.

5. Ministério da Saúde (BR). Secretaria de Atenção à Saúde. Departamento de Atenção Básica. Secretaria de Atenção à Saúde. 0 trabalho do agente comunitário de saúde. Brasília, DF: Ministério da Saúde; 2009.

6. Gil AC. Como classificar as pesquisas. In: Gil AC. Como elaborar projetos de pesquisa. $4^{\mathrm{a}}$ ed. São Paulo: Atlas; 2009. p. 41-56.

7. Minayo MCS. O desafio do conhecimento: pesquisa qualitativa em saúde. $10^{a}$ ed. São Paulo: Hucitec; 2007.

8. Bolfarine H, Wilton OB. Elementos de amostragem. $1^{\text {a }}$ ed. São Paulo: Blucher; 2005. Noções básicas. p.1-35.

9. American Heart Association. Aspectos mais relevantes das diretrizes da American Heart Association sobre ressuscitação cardiopulmonar e atendimento cardiovascular de emergência. Currents [internet]. Dez/05-fev/06 [acesso em 2010 Ago 19];(16):[1-27]. Disponível em:

www.americanheart.org/downloadable/heart/1141072864029CurrentsPortugueseWinter2005-2006.pdf.

10. Ministério da Saúde (BR). Fundação Oswaldo Cruz (FIOCRUZ). Manual de primeiros socorros (Nubio) [internet]. $1^{\text {a }}$ ed. Rio de Janeiro; 2003 [acesso em 2012 maio 13]. Disponível em: http://www.anvisa.gov.br/reblas/manual_primeiros_socorros.pdf. 


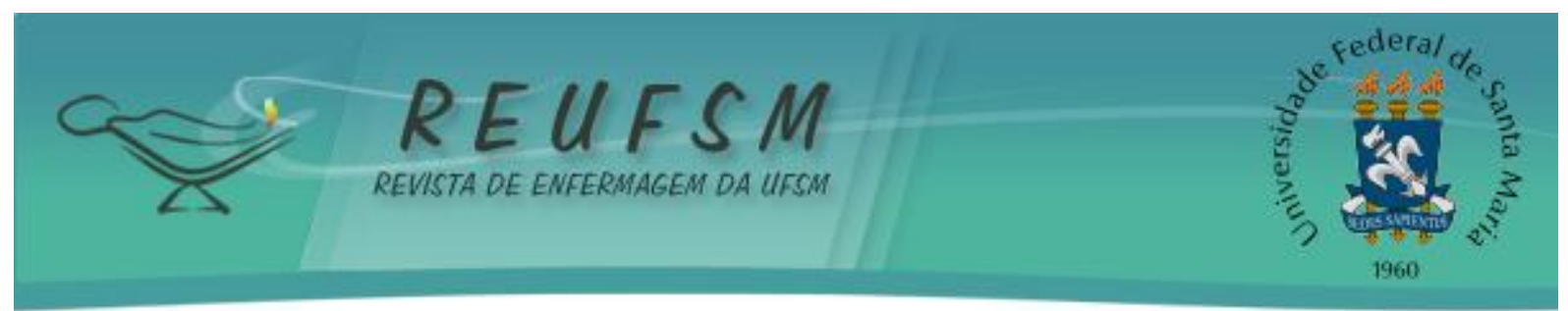

11. Pavelquiere S, Marçal AA, Gomes CPML. Manobras avançadas de suporte ao trauma e emergências cardiovasculares (MAST). $5^{\text {a }}$ ed. (Manual do curso MAST). Marília; 2002.

12. Ministério da Saúde (BR). Conselho Nacional de Saúde. Comissão Nacional de Ética em Pesquisa. Resolução n ${ }^{\circ} 196$, de 10 de outubro de 1996: diretrizes e normas regulamentadoras de pesquisa envolvendo seres humanos. Brasília (DF), 1996 [acesso em 2012 maio 13]. Disponível em: conselho.saude.gov.br/resolucoes/1996/reso196.doc.

13. Bardin L. Análise de conteúdo. Lisboa: Presses Universitaires de France; 2008.

14. Ministério da Saúde (BR). Secretaria de Atenção à Saúde. Departamento de Atenção Básica. Prevenção clínica de doenças cardiovasculares, cerebrovasculares e renais/ Ministério da Saúde, departamento de Atenção Básica - Brasília, 2006.

15. American Heart Association. Destaque das diretrizes da American Heart Association 2010 para RCP e ACE. Mary Fran Hazinski, editora. 2010. Disponível em: ftp://ftp.medicina.ufmg.br/ped/arquivos/Novas_diretrizes.pdf

16. Smeltzer SC, Bare BG, Hinkle JL, Cheever KH. Cuidados aos pacientes com lesão por queimaduras. In: Smeltzer SC, Bare BG, Hinkle JL, et al. Tratado de Enfermagem MédicoCirúrgica. $11^{\text {a }}$ ed. Rio de Janeiro: Guanabara Koogan; 2008. p. 1688-725.

Data de recebimento: $12 / 04 / 2012$

Data de aceite: 29/05/2012

Contato com autor responsável: Juliana Alice de Oliveira Ventorini Endereço: Hercílio Luz, 411, apto 305, centro - Brusque/SC.

CEP: $88350-300$

E-mail: jujuventurni@gmail.com 